Studies in African Linguistics

Volume 42, Number 2, 2013

\title{
TERNARY SPREADING AND THE OCP IN COPPERBELT BEMBA *
}

\author{
Lee S. Bickmore \& Nancy C. Kula \\ University at Albany \& University of Essex
}

\begin{abstract}
Bemba tonology has been described with respect to two prominent claims: $\mathrm{H}$ tone local spreading is binary, and is blocked by the OCP. These claims are based on Bemba, as spoken in Northern Zambia. This paper examines these two claims with respect to contemporary Bemba as it is spoken today in the Copperbelt province of Zambia. This paper shows that in Copperbelt Bemba (CB), these two aspects of $\mathrm{H}$ tone spreading are markedly different. In $\mathrm{CB}$, local spreading is ternary, not binary, and a $\mathrm{H}$ will undergo binary spreading even if it causes an OCP violation. Ternary spread will be shown to follow from two rules: High Tone Doubling and Secondary High Doubling motivated by different constraints within CB tonology. In addition to documenting and describing the behavior of high tone in $\mathrm{CB}$, a comparison to other cases of ternary spreading is also made.
\end{abstract}

\section{Introduction}

The tonology of Bemba is a subject that is considered quite well investigated given the seminal works on Bemba tonology, including Guthrie (1945), Sharman \& Meeussen (1955) and Sharman (1956). Guthrie (1945) looks at nominal tonology while the latter two articles look at verbal tonology. In addition, the work of Mann (1977) and Philippson (1998) also make significant contributions to the study of Bemba tone. ${ }^{1}$ A different and important point of departure of the current paper is the particular Bemba dialect under investigation. All the previous works cited are based on what is called "central Bemba", as spoken in the Bemba heartland in the Northern Province of Zambia and to a large extent based on data collected

\footnotetext{
* The second named author would like to acknowledge financial support from The British Academy grant number SG102315 held between 2011-2013. Both authors acknowledge fruitful discussion with audiences at: Bantu 4, Humboldt University, Berlin; Conference on suprasegmentals, University of Konstanz; ACAL 43 at Tulane University, New Orleans; and the London Phonology Seminar at SOAS, London. All errors are our own. The authors' names appear in alphabetical order.

${ }^{1}$ Other outstanding studies on Bemba grammar and phonology that do not focus on tone are: Hoch (1955), Sambeek (1955), Kashoki (1968), Givón (1970, 1971, 1974, 1976), Hyman (1992, 1994, 1995), Kula (2002), inter alia.
} 
over 50 years ago. In contrast, this paper focuses on newly collected data from Copperbelt Bemba (CB, henceforth) as spoken in central Zambia. A major part of the goal of the paper is to provide a comparison of the two dialects to highlight similarities and differences, as a way of better understanding Copperbelt Bemba tone, and to offer an analysis of hitherto unexamined facts of $\mathrm{CB}$ tone.

There are three central findings with respect to Northern Bemba (NB, henceforth) tonology that are found in the literature cited above and which will be the focus of our comparison with Copperbelt Bemba: (i) local high tone spreading is binary; (ii) high spreading is blocked by the OCP; and (iii) there is unbounded high spread if no high follows. While we have not found any major difference in unbounded spreading (iii), we will show that in $\mathrm{CB}$, the first two properties of NB are markedly different. In $\mathrm{CB}$, local spreading is ternary, not binary, and a high will undergo binary spreading even if it causes an OCP violation (resulting in a phonetic downstep). In addition to documenting and describing the behavior of high tone in $\mathrm{CB}$ and offering an analysis of contemporary $\mathrm{CB}$ tone, we compare our findings on ternary spreading to similar cases in other languages.

The paper is structured as follows. Section 2 provides relevant background on Bemba tone, particularly with respect to those characteristics that are shared by both dialects. Section 3 provides a detailed overview of NB tonology data as discussed in the literature. Section 4 looks at the same facts in $\mathrm{CB}$, highlighting the differences and describing the relevant distributional patterns. Section 5 provides an analysis of the main findings in CB, both in terms of rules and autosegmental representations. Section 6 looks at comparable data on ternary spread and its analysis in different Bantu/African languages. Finally, section 7 offers some concluding remarks.

\section{Basic Bemba tonology}

2.1 Language background. We would like to begin by providing some background to the evolution of $\mathrm{CB}$, and by identifying the population that is the focus of this work. The seminal works of Sharman and Meeussen (1955) and Guthrie (1945) were conducted at a time when there was essentially one main Bemba-speaking area in the north of the country. This situation has changed, however, since the discovery of copper in central Zambia (Copperbelt Province) in the early 1900s leading to major migrations of Bemba-speaking peoples from the north to the Copperbelt, between the 1920s and 1940s. As Kashoki (1972) points out, these migrations brought about a lot of language mixing and led to the emergence of 'Town Bemba', spoken mainly by mine workers from varied language backgrounds. With the continued and fast development of the Copperbelt as a major economic force, migrations continued into the 1960s, with immigrants seeking employment in many different sectors. The Copperbelt thus evolved into a major hub of Bemba-speaking people, with many indigenous Bemba speakers. With a settlement span of 70-80 years, we feel that a consideration of systematic differences between Copperbelt and Northern Bemba is due. Our focus is, however, not on the so called 
'Town Bemba' which is characterized as used by select groups and as being in continuous fluctuation, particularly with respect to vocabulary items (Spitulnik 1999, Kashoki 1972). We rather investigate the Bemba that is used by inhabitants of the Copperbelt who are not necessarily connected with copper mining, but who form part of the now established Bemba settlements. Although CB is the dominant language of the Copperbelt and used as a second language and lingua franca, many other Zambian languages are also present, with a sizeable Lamba population from the main original inhabitants of the Copperbelt. Our data are drawn strictly from native speakers of the Copperbelt. ${ }^{2}$

2.2 Core Bemba tone structure. The facts we describe in this section are tonal facts that are shared by both dialects, and so we refer mainly to general Bemba. Throughout the paper, we provide a sizeable number of examples of the phenomenon discussed, particularly with respect to the different tone patterns motivated by different tense-aspect markers, for which there are few examples in the work of Sharman and Meeussen (1955) and Sharman (1956).

As in many Bantu languages vowel length is distinctive in Bemba, as shown in the pairs $(1 \mathrm{a}-\mathrm{b})$ and $(1 \mathrm{c}-\mathrm{d})$.
a. ú-kú-shík-á
'to be deep'
b. ú-kú-shíík-á
'to bury'
c. ù-kù-tùl-à
'to pierce'
d. ù̀-kù-tùùl-à
'to offer (offering)'

The possible surface tonal patterns in Bemba are given by syllable in (2) below. Thus, a level low, level high and a long falling tone are permissible. Rising tones are disallowed in the language, and are generally resolved to a level low tone as will be seen in section 3 . We posit the mora as the tone-bearing unit in Bemba, which is supported by the spreading patterns in the language, to be examined below.

(2) Cà Càà Cá Cáá Càà ${ }^{*}$ Càá

We follow much previous work in Bantu in assuming that the underlying tonal contrast in Bemba is one of high tone versus toneless, with a low tone being inserted quite late in the phonology.

\footnotetext{
${ }^{2} \mathrm{CB}$ data are drawn from speakers mainly based in Ndola as well as from the second author. We would like to thank the consultants we worked with for both CB and NB dialects: Honoria Mutale, Bupe Kula, Moses Nkandu, Catherine Mambwe, Godfrey Mwewa, Mubanga Kashoki, Joseph Mwansa, Fr. Kabiti, Oscar Mukabila, and Mukanu Kapalanga.
} 
It is important to note that tones in Bemba are both lexical and grammatical. Lexical tones include those found underlyingly on roots and affixes. This contrast on verb roots can be seen in the CB examples in (3).
a. lùk-á
'weave!'
b. lúk-á
'vomit!'

Other lexical Hs include those on Subject Markers and Object Markers. For Subject Markers, the $2^{\text {nd }}$ and $3^{\text {rd }}$ person markers within Class 1 are toneless while all others are H. For Object Markers, the class 1 singulars are toneless, while all other OMs are H. Multiple examples of these markers will be presented in the examples below and their underlying tonal status is clearly indicated in the accompanying underlying representations.

The second type of $\mathrm{H}$ tone found in the language is referred to in the literature as a melodic high $(\mathrm{MH}){ }^{3}$ Melodic high tones are morphosyntactically assigned by various tense, aspect and mood markers (TAMs) to the verb stem. In Bemba TAMs form four groups with respect to whether and how they contribute an $\mathrm{MH}$. The following discussion presents our own analyses of the relevant TAMs but does not differ in content from Sharman \& Meeussen (1955) and Sharman (1956). The spreading patterns of the lexical tones of the TAMs are subject to the tone rules of the language, discussed in sections 3 and 4 . As will be seen directly below, some TAMs show different tonal melodies depending on whether an object marker $(\mathrm{OM})$ is part of the verb or not. For ease of exposition, MHs are presented beginning with forms that require the least reference to the tonal rules yet to be discussed. ${ }^{4}$

First, there are a number of TAMs which do not provide any MHs, i.e., the only highs present are lexical ones. These TAMs include those listed in (4). Several full, representative verb forms are given in (5).

TAMs with no MH:

Infinitive, Future (/ka-/), Habitual (/la-/), Progressive (/lée-/), Past Progressive (/a-lée-/), Desiderative 1 (/ka-lée/), Nearer Past (/á-cí-/), Immediate Future (/á-láa/),

\footnotetext{
${ }^{3}$ For descriptions of and evidence for the MH in other languages, see, inter alia, Hyman \& Byarushengo (1984), Goldsmith (1987), Odden (1987), Hyman \& Katamba (1993), and Hyman \& Ngunga (1994), and Bickmore (1997, 2000, 2007).

${ }^{4}$ The delineation of the verb follows the standard Bantu structure unless noted: SM (subject marker) + TAM (tense, aspect, mood markers) + VB (verbal base $=$ verb root + suffixes $)+$ FV (final vowel). An object marker (OM) may also optionally occur between TAM and VB; the glossing/translations will usually make this clear. With respect to melodic highs the following abbreviations will be used in the underlying representations: $\mathrm{HF}=\mathrm{MH}$ on the final; $\mathrm{H} 2-\mathrm{F}=\mathrm{MH}$ from $\mathrm{V} 2$ to the final; $\mathrm{H} 2=\mathrm{MH}$ only on V2 (V2 = vowel following the first vowel of the VB). Predictable vowel length, such as occurs before NC clusters, is not represented in Bemba orthography but we show all long vowels in the output forms, since they have an impact on tone spread.
} 
Continuous (/á-cí-láa/), Future Continuous (/ka-láa/), Imperative 2 (á-lii-), Hypothetical Continuous (preverbal /a-/, /láa-/), Desiderative 2 (/leé-/)
a. tù-kà-pàt-à
'we will hate'
/tu-ka-pat-a/
b. tù-là-pàt-à
'we usually hate'
/tu-la-pata/
c. tù-léé-pát-á
'we are hating'
/tu-lée-pat-a/
d. tw-àà-léé-pát-á
'we were hating'
/tu-a-lée-pat-a/

In all data presentations henceforth, the right hand side form, in slashes, gives the underlying representation with the underlying lexical tones. The left-hand side is the surface form. In (5ab) in the Future and Habitual, respectively, since the 1st plural subject marker /tu-/, the tense marker, and the verb root/pat/ are all toneless, the forms surface with low tones. This indicates that the TAM marker does not add any MHs to the verb stem. In (5c-d) with the Progressive and Past Progressive, respectively, the source of the high tone is the progressive marker /lée-/, which spreads its high to the end of the verb with no imposed grammatical tones. This is a demonstration of unbounded high spread which will be discussed in detail in sub-section 3.1.

The second group of TAMs are those which assign an MH to the Final Vowel. These include the Imperative with a high toned Root and no OM, the Subjunctive without an OM, and the Negative Perfective. An example of each is given below.
a. béléèng-á
'read!'
/béleng-a $+\mathrm{H}_{\mathrm{F}} /$
b. tú-béléèng-é
'we should read'
/tú-béleng-e $+\mathrm{H}_{\mathrm{F}} /$
c. tà-tú-bélééng-èlé
'we have not read'
/ta-tú-béleng-ile $+\mathrm{H}_{\mathrm{F}} /$

In the Imperative in (6a), the Subjunctive without OM in (6b), and the Negative Perfective in (6c), there is an additional $\mathrm{H}$ tone present, which is not lexically associated with any of the morphemes present. In these examples, this MH surfaces on the Final Vowel.

The third group of TAMs are those which assign an MH to the second syllable of the stem, up to and including the Final Vowel. These include those listed in (7). Several full verbal forms are given in (8).

(7) TAMs assigning a MH on pen-initial through final syllable:

Perfect (/-ile/), 'already', Past (/a-, -a/), Subjunctive (with OM), Imperative (with OM), Remote Past (/a-, ile/), Imperative 1 (pre-verbal /náa-/), Hypothetical (pre-verbal/a-/) 

a. tù-lòòndólw-éélé 'we have introduced'
/tu-londolol-ile $+\mathrm{H}_{2-\mathrm{F}} /$
b. tù-mù-lòòndólól-é
'we should introduce him/her'
/tu-mu-londolol-e $+\mathrm{H}_{2-\mathrm{F}} /$
c. tw-àà-lòòndólw-éélé
'we introduced/explained'
/tu-a-londolol-ile $+\mathrm{H}_{2-\mathrm{F}} /$

All of the examples in (8) are composed of toneless morphemes. Yet in each case we see a High Tone Span on the surface, beginning with the second syllable of the stem (which in each case begins with the verb root/londolol-/) and continuing through to the end of the word. This is the result of the TAM contributing an MH to the form, which docks onto all stem TBUs except the initial syllable.

Finally, there is one TAM, the Imperative with a toneless root and no OM, which assigns an $\mathrm{MH}$ to the second syllable of the verb stem. This is illustrated in (9).

(9) lòòndólwèèl-à 'introduce (applic)' /londolol-il-a $\mathrm{H}_{2} /$

As already pointed out, the range of TAMs and MHs that are associated to them are the same in both NB and CB. As we have seen, there are four different MH patterns that interact with the tone rules of the language. We turn now to an investigation of NB as reported in the literature.

\section{Tonal patterns in the verb in Northern Bemba}

Our main sources for the tonal structure of NB in this investigation are Sharman \& Meeussen (1955) and Mann (1977). Sharman and Meeussen (1955) recognize the following tonal properties of particular tenses in NB.

(10) Constraints on NB tonology according to TAMs (Sharman \& Meeussen 1955: 393-4)
a. $+\mathrm{O}=$ with zero post-radical tones
b. $+\mathrm{D}=$ with diatony (all syllables high after rightmost high)
c. $+\mathrm{P}=$ with post-radical high tones
d. $+\mathrm{F}=$ with final high
e. $+\mathrm{R}=$ with raised final

We can draw correlations between the constraints in (10) and our discussion in section 2. (10a) is equivalent to MH pattern (i) in section 2 (see (4), (5)). (10b) follows from high tone spreading rules (see section 4.1) and thus need not be treated as part of the tense system. (10c) is equivalent to the third MH pattern (see (7), (8)), and (10d-e) is equivalent to the second MH pattern (see (6)). These are also summarized in (Sharman \& Meeussen 1955: 395), as 
representing 'imposed tone patterns'. ${ }^{5}$ Sharman \& Meeussen (1955) thus treat surface tone patterns as resulting from two sources: tones imposed by particular tenses (melodic highs), and tone patterns resulting from tonal processes, as well as the interaction of the two. Having already discussed the former we now focus on the active tonal rules of NB.

3.1 Binary and unbounded spreading in NB. One of the hallmark properties claimed for NB is tone doubling, which doubles a high tone onto a following TBU. However, a major constraint on this tone doubling is that it does not apply if it would result in a form with adjacent high tones, i.e., doubling is always blocked by the OCP (Obligatory Contour Principle). Consider the examples in (11); examples (11a, c) from Sharman \& Meeussen (1955) and (11b, d) from Mann (1977). ${ }^{6}$
a. bá-ká-fik-à (kumumana)
'they will arrive at the river'
/bá-ka-fik-a/
b. bá-ká-bìl-à (mailo) 'they will sew tomorrow'
/bá-ka-bil-a/
c. bá-ka-pít-á (mumusebo)
'they will pass in the road'
/bá-ka-pít-a/
d. bá-ka-cáp-á (mailo)
'they will wash tomorrow'
/bá-ka-cáp-a/

The examples in (11a-b) exhibit binary tone spread, or tone doubling, as we will refer to it, where the underlying $\mathrm{H}$ on the subject marker - $b a$ - spreads to the otherwise toneless future marker $-k a$ - This contrasts with $(11 \mathrm{c}-\mathrm{d})$ where binary spread is blocked because in both cases the verb root, which immediately follows $-k a-$, is lexically high. Thus, the high tone of -bádoes not spread to the future marker $-k a$ - because this would result in a high tone adjacenct to the lexical high tone on the verb root.

An important point to note here is that both binary and unbounded spreading occur in the language. The type of spreading that affects a particular $\mathrm{H}$ has both phrasal and tonal conditions. If a verb form is phrase final, i.e., not followed by any other constituent, then the rightmost $\mathrm{H}$ in that form will undergo unbounded spreading. All other Hs undergo binary spreading. Unbounded spreading, or what Sharman \& Meeussen (1955) call diatony, is illustrated in (12a-b), where the $\mathrm{H}$ on the SM spreads to the end of the word. If the $\mathrm{H}$ is not in a phrase-final word (11a-b) or is followed by another $\mathrm{H}$ within the same word (12c-d), then binary, rather than unbounded, spreading occurs. Examples (12a, c) are drawn from Sharman \& Meeussen (1955) and (12b, d) from Mann (1977).
a. bá-ká-fík-á
'they will arrive'
/bá-ka-fik-a/
b. bá-ká-bíl-á
'they will sew'
/bá-ka-bil-a/

\footnotetext{
${ }^{5}$ We leave out of this list less general patterns that Sharman \& Meeussen (1955) include in their 'imposed patterns' list since all can be derived, in particular: tenses with subjunctive imposed patterns, forms with contrast, tenses with low prefix, and tenses with determinants.

${ }^{6} \mathrm{We}$ add the parenthesized words here simply to show that the verbs presented are in their non-phrasefinal form.
} 

c. tú-lúb-ùl-ùl-é
'we should explain'
/tú-lub-ul-ul-e $+\mathrm{H}_{\mathrm{F}}$ /
d. bá-á-kùùl-á
'they have built'
/bá-a-kuul-a $+\mathrm{H}_{2-\mathrm{F}}$ /

The rules of bounded spreading (binary spread in NB) and unbounded spreading define the two central tone rules of Bemba tonology. We summarize these in (13).

\section{(13) High Tone Spread (HTS) in NB:}
a. unbounded spread applies to the rightmost high tone in a verb form that is phrase final
b. bounded spreading (binary spread) occurs to a rightmost high tone in a verb form that is non-phrase final
c. bounded spreading (binary spread) occurs to a high tone in a verb form if a subsequent high occurs within the verb form
d. bounded spreading (binary spread) is subject to the OCP
e. bounded spreading (binary spread) can spread onto the final vowel in a verb form

3.2 Tonal processes in NB. There are a number of other tone rules that Sharman \& Meeussen (1955) discuss that we will touch on here briefly because they interact with the main tone rules in (13). Consider, for example, how HL and LH sequences of tones are resolved when they occur on a long vowel, as a result of vowel fusion or a glide formation process. As noted earlier, there are no surface rising tone sequences as these are generally resolved as a level low tone, unless an OCP violation must be avoided; in which case a level high results (see discussion below). HL, on the other hand, will resolve to HH by HTS, following the productive spreading processes in (13), or will remain as HL to avoid an OCP violation if another $\mathrm{H}$ follows. Consider the following examples from Sharman \& Meeussen (1955: 394).

\section{(14) rising and falling tone resolution}
a. tw-àà-fík-á
'we have arrived'
/tu-á-fik-a/
b. tw-áá-kù-láá-táp-á
'we will be drawing (water)'
/tu-á-ku-láa-tap-a/
c. tw-àà-pít-á
'we have passed
/tu-á-pít-a/
d. bá-á-fìk-ílé
'they arrived'
/bá-a-fik-ile $+\mathrm{H}_{2-\mathrm{F}} /$
e. bá-à-pít-ílé
'they passed'
/bá-a-pít-ile $+\mathrm{H}_{2-\mathrm{F}} /$

Examples (14a-c) are cases where a LH sequence (rising tone) would result after the -u- of the subject marker - tu- undergoes gliding, with only the second vowel of the resultant long vowel bearing a high tone. In (14a) the high tone undergoes unbounded spreading, following (13a). This creates a rising tone on the first syllable, which gets resolved to a level Low. In (14b) the 
$\mathrm{H}$ on $-a$ - cannot spread to the next syllable, as this would result in an OCP violation. (OCP violations in $\mathrm{CB}$ are discussed extensively below in section 4.2.) The only way to realize the $\mathrm{H}$ and also avoid a rise is to resolve the rise in this case to a level $\mathrm{H}$. The second high in this word undergoes unbounded spreading. In (14c) the LH resolves to a level low tone when it is immediately followed by another $\mathrm{H}$. These examples show that various repair strategies are employed to prevent a rising tone from ever surfacing. (14d-e) are cases where a falling tone (HL) would result from vowel fusion. In (14d) which has a toneless verb but also a V2-F $\mathrm{MH}$, the high tone of $-b a ́$ - spreads to the following mora creating a level $\mathrm{H}$ tone. The one case where an underlying Fall does not become a level $\mathrm{H}$ is illustrated in $(14 \mathrm{e})$, where spread of the $\mathrm{H}$ on $-b a ́$ - is further blocked as it would result in an OCP violation. ${ }^{7}$

Only two other central points remain in the description and analysis of NB by Sharman \& Meeussen (1955). One is their treatment of monophone subject markers as systematically different from their diphone counterparts with respect to tone; the other refers to floating tones which are associated with particular TAMs. On the latter, floating tones are restricted to pre-initial elements that occur before the subject marker as given in (15) below. Sharman \& Meeussen (1955: 399) refer to these elements as 'tonal determinants' because they determine the tone of a following syllable.

(15) Floating tone in pre-initial elements
a. a-H-
remote past
b. naa-H-
effects seen at time now
c. ta-H- negatives of remote past, recent past, earlier today, now
d. ta-L- negatives of simple future tenses 8

The docking of these floating tones onto the following syllable is subject to the constraints in (13), although because they are floating tones they are not subject to the OCP with a following high. Thus a form like /a-H-tu-lábilila/ 'had we totally forgotten', surfaces as $a$-túlábililá with the high tones of -tú- and -láb- adjacent. Monophone prefixes behave in a similar manner to pre-initial elements in that, although they can host their high tone, they tend to realize their high tone on the following syllable, as long as the constraints in (13) are satisfied. Consider the forms in (16) where it appears that the $2^{\text {nd }}$ and $3^{\text {rd }}$ person singular subject

\footnotetext{
${ }^{7}$ Note that the application of the OCP in NB is a case of a derived environment effect, since lexical adjacent highs are allowed, as seen in (14e) where the high tone of the $\mathrm{MH}$ and the lexical high tone of the verb are adjacent.

${ }^{8}$ An example of this can be seen in a form such as /ta-L-bá-a-lek-e $+\mathrm{HF} /$ 'they will not stop' which surfaces as ta-baa-lek-é where the $\mathrm{H}$ on /ba-/ does not surface. While one possible analysis of this would be to posit an underlying $\mathrm{L}$ which displaces the following $\mathrm{H}$, it also seems possible to account for this assuming some tonal allomorphy of Subject Markers. As this does not directly bear on our analysis, we leave it as an open question.
} 
markers vary with respect to whether they appear with a high tone or not (examples from Sharman \& Meeussen 1955: 395).

(16) Monophone subject markers
a. à-ká-fík-a (mailo)
'he/she will arrive (tomorrow)'
/á-ka-fik-a/
b. á-kà-túm-á
'he/she will send'
/á-ka-túm-a/
c. w-àà-fík-á
'you have arrived'
/ú-a-fik-a/
d. w-áá-fùl-ílé (kale)
'you missed (a long time ago)'
/ú-a-ful-ile $+\mathrm{H}_{2-\mathrm{F}} /$

(16a) contrasts with (16b) in that the verb is lexically toneless in the former but high-toned in the latter. Thus in (16a) the high tone of the subject marker /á-/ can shift to the following syllable and undergo binary spread because there is a constituent following the verb, the adverb tomorrow. In (16b), on the other hand, High Tone Shift cannot occur without a violation of the OCP and so the high tone remains on the subject marker. The same applies to the forms of the $2^{\text {nd }} \mathrm{sg}$. In (16c) the high tone of /ú-/ shifts and spreads onto the toneless verb but in (16d), which has a V2-F MH, the high tone of the subject marker stays on the long vowel resulting from gliding. The behavior of the tone in (16), in contrast to the forms in (15), provide support for treating monophone subject markers as lexically associated with high tone. This high tone undergoes tone shift to the next syllable and is subject to the OCP, unlike floating high tones.

As demonstrated in the foregoing, High Tone Spread in bounded and unbounded contexts are the two main tone rules that apply in NB. These rules interact with MHs as determined by particular tenses, floating tones in pre-initial elements, the resolution of resultant rising tones and tone shift in monophone subject markers. We now turn to an evaluation of these phenomena in Copperbelt Bemba.

\section{Tonal patterns in Copperbelt Bemba}

As with NB we will evaluate the manifestation of unbounded High Spread, bounded binary spread and the role of the OCP in HTS. In addition, we will look in more detail at HTS across word boundaries in both verbal and nominal forms.

4.1 Unbounded and bounded spreading in CB. Unbounded spreading in CB applies in the same manner as in NB, with a rightmost $\mathrm{H}$ undergoing unbounded spread in phrase-final forms. This is illustrated by the examples below, which are parallel to the NB forms in (12ab).
a. bá-ká-fík-á
'they will arrive'
/bá-ka-fik-a/
b. bá-ká-mú-lóóndólól-á
‘they will introduce him/her' /bá-ka-mu-londolol-a/ 


$\begin{array}{lll}\text { c. bá-lá-mú-lúk-íl-á } & \text { 'they weave for him/her' } & \text { /bá-la-mu-luk-il-a/ } \\ \text { d. tù-kà-páápáátík-á } & \text { 'we will flatten' } & \text { /tu-ka-páapaatik-a/ } \\ \text { e. tù-là-páápáátík-á } & \text { 'we flatten' } & \text { /tu-la-páapaatik-a/ } \\ \text { f. ú-kú-lóóndólól-á } & \text { 'to introduce' } & \text { /ú-ku-londolol-a/ } \\ \text { g. ú-mú-límí } & \text { 'farmer' } & \text { /ú-mu-limi/ }\end{array}$

In each case in (17), the lone high in the underlying representation spreads rightwards in an unbounded fashion, since all these forms are in phrase final position. The process affects Subject Markers, roots, as well as the pre-prefix and is thus not tied to the morphological status of the morpheme that bears the high tone.

In contrast to $\mathrm{NB}$, where bounded spreading is always binary, in $\mathrm{CB}$ it is maximally ternary, i.e., it often spreads to the following two moras rather than just one. This ternary spreading occurs in the same context in which binary spreading occurs in NB: in non-phrase final forms and in cases where the spreading $\mathrm{H}$ is followed by another $\mathrm{H}$ within the stem $(13 b, c)$.

In order to tease out whether ternary spreading is sensitive to moraic structure or syllabic structure or both, we now examine it in different prosodic environments. We consider first examples where the input high is on a short vowel. In these cases it spreads through the following syllable and up to the first mora of the syllable that follows. The post-verbal class 17 locative clitic /kó/ is used as the post-verbal constituent. ${ }^{9}$
a. bá-ká-pát-à kó
'they will hate'
/bá-ka-pat-a kó/
b. bá-mú-lúk-ill-à kó
'they weave for him/her' /bá-luk-il-a kó/
c. bá-ká-shíik-à kó
'they will bury'
/bá-ka-shiik-a kó/
d. bá-ká-lóòdòlòl-à kó
'they will introduce'
/bá-ka-londolol-a kó/
e. bá-ké-émb-íl-à kó
'they will dig for'
/bá-ka-imb-il-a kó/
f. bá-lóóndólòl-é
'that they introduce'
/bá-londolol-e $+\mathrm{H}_{\mathrm{F}}$ /
g. tù-kà-bá-lóóndólòl-à kó
'we will introduce them'
/tu-ka-bá-londolol-a kó/
h. tù-kà-bélééng-él-àn-à kó
'we will read for e.o.'
/tu-ka-béleng-il-an-a kó/

In examples (18a-b) the two syllables following the underlying $\mathrm{H}$ have short vowels. In these cases the $\mathrm{H}$ of the subject marker bá- spreads in a clear ternary pattern onto these two following syllables. In (18c-d) the underlying $\mathrm{H}$ is followed by a short and then long vowel. Here the $\mathrm{H}$ spreads through the second syllable and onto the first mora of the third, producing a Falling tone. In each of these four cases, then, the H spreads to the following two morae.

\footnotetext{
${ }^{9}$ The post-verbal clitic /kó/, though deriving from a locative, has developed a number of additional readings including being a substitutive applicative with an 'on behalf of' reading, a partitive reading or a politeness reading; see Marten \& Kula (to appear) for discussion. Given this optionality in interpretation we have decided to leave the /kó/ meaning unspecified in the glosses.
} 
However, the pattern is not always quite this simple, as seen in examples (18e-h), where the syllable following the underlying $\mathrm{H}$ has a long vowel. In these cases the $\mathrm{H}$ spreads through both morae of the second syllable and onto the first mora of the third syllable. In terms of the number of morae where the $\mathrm{H}$ has spread in (18), we see that it spreads onto the following two morae in (18a-d), but onto the following three morae in (18e-h).

What is consistent about the forms in (18) is that the $\mathrm{H}$ spreads up to the first mora of the third syllable. We now examine one more set of forms, which complicates this further. In the forms below, the spreading $\mathrm{H}$ is underlyingly on the first mora of a long vowel. As can be seen the $\mathrm{H}$ spreads through the second, tautosyllabic mora, and onto the first mora of the following syllable.
a. tù-kà-léét-él-àn-à kó
'we will bring for e.o.'
/tu-ka-léet-il-an-a kó/
b. tù-léé-lóòndòlòl-à kó
'we are introducing'
/tu-lée-londolol-a kó/
c. tw-àà-léé-mw-iìmb-ill-à kó
'we used to dig for him' /tu-a-lée-mu-imb-il-a kó/

(19b-c) show that when the syllable following the source high tone is also long, spreading creates a fall on that syllable. This, and the examples in (18), demonstrate the specific patterns involved in ternary spreading. The process is local and not unbounded because HTS does not continue even when there are available targets, and stops short within a long vowel. We will take up the task of formalizing this process below in section 5, but now simply summarize the patterns evident in the examples presented thus far. In ternary spread in $\mathrm{CB}$ a high tone on a monomoraic syllable spreads to the first mora of the third syllable, but if it begins on the first mora of a long vowel, it spreads to the first mora of the second syllable. This again supports the mora as the TBU in $\mathrm{CB}$.

Let us now examine some restrictions on this ternary spreading. One major constraint is that the ternary portion of the spread (i.e., spreading beyond the immediately following mora), never extends to the final vowel of the verb stem. This is illustrated in (20).

a. tù-kà-lás-íl-à kà-fúúnd-ísh-á 'we will hit for the teacher'
/tu-ka-lás-il-a ka-fúnd-ish-a/

b. tù-kà-bá-shíík-à bwì̀nò

'we will bury them well' /tu-ka-bá-shiik-a buino/

Given the patterns detailed in (18)-(19) above, we would expect the $\mathrm{H}$ within the first word in each case to spread onto the word-final vowel, but it does not. We note that the lack of spreading to the word-final vowel cannot be due to an OCP constraint, since the following word in each case starts with a low tone. Thus, unlike NB, bounded (ternary) spread in CB does not spread to the final vowel of a verb form. 
We begin the next sub-section by first considering the linguistic status of ternary spread in $\mathrm{CB}$, before providing an analysis of the process.

4.2 Ternary spreading as phonological. An important question at this stage is to evaluate whether ternary spread in CB is phonological and not merely a phonetic effect. It has been suggested that some claimed cases of $\mathrm{H}$ spreading are really just due to the phonetic implementation of $\mathrm{F}_{0}$ where the high pitch simply extends a bit beyond its target (see, e.g., Myers 1999, Kaplan 2008). One might reasonably ask if this is applicable in the CB case, i.e., might it simply be that $\mathrm{CB}$ has the same Tone Doubling process as NB onto the following mora, and that what is being marked as high-toned morae beyond that is simply some phonetic overshoot? One way of testing this is by finding a pair of words that differ minimally underlyingly, where the tone rules of one dialect predict a complete neutralization, while the rules in the other dialect do not. We tested this with the CB examples in (21), which are identical underlyingly, except for the tone of the Object Marker, which occurs immediately before the verb root. The form in (21a) contains the high-toned second person plural OM /mú-/ while (21b) contains the toneless third person singular /mu-/. Both verb forms include the H-toned SM /bá-/ followed by the high-toned Past of Today /-á-cí-/. In (21a) the source of HTS is /mú/ which spreads one mora to the right within the verb but will not continue to spread onto the word-final TBU. In (21b), on the other hand, where the source of high spreading is the /cí-/ of the past tense marker there is enough room for ternary spread to apply and it does so, onto the two morae of the following long vowel. This then results in a complete surface tonal neutralization for CB speakers, as indicated by the transcriptions. This can be accounted for only if ternary spread applies in (21b). If ternary spread did not apply here (as it is argued never to do in NB) then the ungrammatical starred form in (21b) would surface, i.e., with a fall on the long vowel of the verb. This predicts that these forms are distinct for NB speakers who produce the starred form in (21b). Our NB speakers confirm this distinction.

a. bá-á-cí-mw-í́mb-à kó 'they just dug you (pl) up'
/bá-á-cí-mú-imb-a kó/

b. bá-á-cí-mw-ímb-à kó 'they just dug him/her up'

/bá-á-cí-mu-imb-a kó/ (*bá-á-cí-mw-î̀mb-à)

A similar scenario involving differences in neutralization is given by the examples below in (22). The only difference in the underlying representations is that (22a) contains the H-toned verb root /lúk/ 'vomit' while (22b) contains the toneless verb root/luk/ 'weave'. In (22a) the final part of ternary spreading is blocked, resulting in a fall on the penult because a high tone follows (MH) and ternary spread is subject to the OCP (see full discussion to follow in section $4.2)$. In (22b) with a toneless verb stem ternary spread takes place, also creating a fall on the 
penult and neutralizing the contrast between the two forms. For CB native speakers these forms are completely identical and cannot be distinguished. However, in NB, where there is no rule of ternary spread, the forms are distinct. In this case, the $\mathrm{H}$ on /tú-/ in (22b) will spread a single mora to the right, onto the verb root. This leaves the penult to surface as a long Low as shown in the starred form of $(22 b)$.
a. tà-tú-lúk-îil-é
'we have not vomited on'
/ta-tú-lúk-iil-e $+\mathrm{H}_{\mathrm{F}} /$
b. tà-tú-lúk-îil-é
'we have not woven for'
/ta-tú-luk-iil-e $+\mathrm{H}_{\mathrm{F}} /$
(*tà-tú-lúk-ìil-é)

We thus confidently conclude that ternary spreading in CB is phonological, and not simply a low-level product of phonetic implementation.

We now turn to the question of how to characterize and formalize ternary spreading in CB. We propose that ternary spreading does not consist of a single rule in $\mathrm{CB}$ but a combination of a rule of binary spread followed by another rule of secondary spread. These two rules together achieve the attested ternary effect. The two rules are defined in (23) below.

(23) a. High Doubling: spreads a $\mathrm{H}$ a single mora to the right

b. Secondary High Doubling: further spreads the $\mathrm{H}$ up to the first mora of the following syllable

The two rules in (23) must be treated as independent rules because they are subject to different constraints. One difference between High Doubling and Secondary High Doubling in CB is that while Secondary High Doubling cannot spread onto the final vowel of a stem, High Doubling can. This is illustrated in the examples below, contrasting (24a-b) with the examples presented above in (20a-b).
a. tù-kà-lúk-á sáàná
'we will vomit a lot'
/tu-ka-lúk-a sáaná/
b. tù-kà-lás-á sáàná
'we will hit a lot'
/tu-ka-lás-a sáaná/

In (24a-b) High Doubling applies and results in spreading the $\mathrm{H}$ onto the word-final TBU. In (20a-b), however, while HD has applied, Secondary High Doubling has not, as the later process does not spread a $\mathrm{H}$ onto a word-final TBU. This provides the first piece of evidence that the two processes behave differently. We find further justification for two independent tone-doubling rules in our investigation of OCP effects in $\mathrm{CB}$ in the following sub-section.

4.3 OCP effects in Copperbelt Bemba. Recall from (11c-d) that in NB binary H spread is blocked by the OCP, so that a high tone does not spread if the output would result in adjacency between high tones. By contrast, the OCP does not constrain High Doubling (23a) in CB. Spreading occurs in these cases, resulting in a downstep because of the following 
lexical or melodic high, as the examples below show.
a. bá-ká-'lás-á
b. bá-ká-'páápáátík-á
c. ú-kú-'léét-á
d. ú-kú-'ly-á
e. bá-lú!k-ílé
f. kálín-á
g. bá-pátt-é

'they will hit'

/bá-ka-lás-a/

'they will flatten'

/bá-ka-páapaatik-a/

'to bring'

/ú-ku-léet-a/

'to eat'

/ú-ku-lí-a/

'they have woven'

/bá-luk-ile $+\mathrm{H}_{2 \mathrm{~F}} /$

'be nervous!'

'hate them!'

/kálip-a $+\mathrm{H}_{\mathrm{F}} /$

/bá-pat-e $+\mathrm{H}_{\mathrm{F}} /$

As stated in (13c) bounded spread is expected in these forms because a high tone (either lexical or melodic) follows the source high tone within the verb form. As seen in these cases High Doubling applies, spreading the $\mathrm{H}$ to the following mora, resulting in a downstep on the following syllable. The rightmost high in each form can be seen to undergo unbounded spread as expected (13a).

Following Odden's (1986) analysis of Kishambaa, we assume that downstep can be structurally defined as occurring between two TBUs linked to distinct $\mathrm{H}$ tones, therefore not requiring any floating $\mathrm{L}$ in a language that otherwise is best analyzed as contrasting $\mathrm{H}$ vs. $\varnothing$, rather than $\mathrm{H}$ vs. $\mathrm{L}$, as we claim for Bemba. ${ }^{10}$ Thus, the first two TBUs in an example such as (25a) are linked to the same $\mathrm{H}$ after spreading, and therefore are pronounced on the same $\mathrm{H}$ pitch, whereas the second and third TBUs are linked to distinct Hs and are therefore separated by a downstep. Finally, we note that in Bemba downstep always occurs as a phonologically derived OCP violation. Underlyingly adjacent TBUs linked to distinct Hs do not create any downstep, and therefore we assume that such Hs undergo a process of $\mathrm{H}$ Fusion before the spreading rules apply. This is illustrated in e.g., (21a-b), (22a) and (26b).

One way to substantiate our claim that High Doubling is in fact applying in these cases (and that what we are transcribing as cv́cv́!cv́ isn't really cv́cv̀cv́) is to set up another potential neutralization context as in (26) below. As can be seen, the two forms are nearly identical underlyingly. The only difference is that the first contains a toneless root, while the second contains a H-toned one. In (26a) the $\mathrm{H}$ on the object marker prefix /shí-/ spreads to the following syllable as expected. If binary spread were blocked by the OCP in CB, High Doubling would not occur in (26b) and the two forms would surface as identical. The two forms, treated as distinct by CB native speakers, differ because the high tone of the verb stem in (26b) spreads to the final vowel, resulting in a downstep on the high tone of the following post-verbal clitic.
a. ú-kú-'shí-lúk-à kó
'to weave it'
/ú-ku-shí-luk-a kó/

\footnotetext{
10 This approach was adopted and justified in some detail for Ekegusii (Bickmore 1997), Namwanga (Bickmore 2000) and Cilungu (Bickmore 2007).
} 

b. ú-kú-'shí-lúk-á 'kó
'to vomit it up'
/ú-ku-shí-lúk-a kó/
(*shí-lúk-à)

In contrast to High Doubling (HD), Secondary High Doubling (SHD) is blocked by the OCP thus providing another context in which the two rules are distinct. Consider the following examples of SHD constrained by the OCP. We consider cases involving differences in length between the syllable containing the underlying $\mathrm{H}$ and the following syllable.

(27) Short - Short (/cŕcvevć́/)
a. bá-ká-mù-lás-á
'they will hit him/her'
/bá-ka-mu-lás-a/
b. bá-mú-lùk-ílé
'they have woven for him/her'
/bá-mu-luk-il-ile $+\mathrm{H}_{2 \mathrm{~F}}$ /
c. tú-lúk-ìl-é
'that we weave for'
/tú-luk-il-e $+\mathrm{H}_{\mathrm{F}}$ /
d. lásh-íl-àn-á
'hit for each other!'
/lás-il-an-a $+\mathrm{H}_{\mathrm{F}} /$
e. kálíp-ìl-á
'be upset at!'
/kálip-il-a $+\mathrm{H}_{\mathrm{F}} /$

As can be seen in the examples in (27) HD applies, but SHD does not because if it did, it would result in an OCP violation with a following high tone (either lexical or a melodic high).

The examples in (28) have the source high tone on a long vowel resulting from vowel fusion (28a), gliding (28b) or a lexically long vowel (28c).

\section{(28) Long - Short (/cv́vcvcv́/)}
a. bá-á-mù-lás-á
'they have already hit him/her'
/bá-a-mu-lás-a $+\mathrm{H}_{2 \mathrm{~F}} /$
b. tw-ímb-ill-é
'that we dig for'
/tú-imb-il-e $+\mathrm{H}_{\mathrm{F}} /$
c. léét-èl-á
'bring for!'
$/$ léét-il-a $+\mathrm{H}_{\mathrm{F}} /$

In each case HD applies, spreading the $\mathrm{H}$ to the following tautosyllabic mora. However, SHD is blocked by the OCP from continuing to spread into the syllable following the $\mathrm{H}$ source. This pattern also further confirms that HTS in CB is based on the mora, since spreading onto the short syllable of a long-short sequence is treated as SHD, which in this case fails to occur to avoid an OCP violation.

The following examples demonstrate a short-long sequence.

(29) Short - Long (/cv́cvvcv́/ \& /cv́cvvcvcv́/)
a. bá-lóòndólw-éélé
'they have introduced'
/bá-londolol-ile $+\mathrm{H}_{2 \mathrm{~F}}$ /
b. béléèng-á 'read!'
/béleng-a $+\mathrm{H}_{\mathrm{F}}$ /
c. bá-shíik-íl-é
'bury for them!'
/bá-shiik-il-e $+\mathrm{H}_{2 \mathrm{~F}}$ /
d. bélééng-èl-á
'read for!'
/béleng-il-a $+\mathrm{H}_{\mathrm{F}} /$
e. tú-shík-ill-é
'that we bury for'
/tú-shiik-il-e $+\mathrm{H}_{\mathrm{F}}$ / 
In (29a-b), after HD applies, SHD is blocked completely, since spreading onto the second mora of the second syllable would violate the OCP. In (29d-e), however, SHD can spread the $\mathrm{H}$ one additional mora, onto the second mora of the long vowel, without violating the OCP. There is no additional spread after this as it would violate the OCP. Thus, in the cases where SHD has the potential to spread up to two additional morae beyond HD, it does so, as long as it does not violate the OCP. This shows that SHD is not an all-or-nothing spreading rule, but can also apply partially. Furthermore, each discrete spread to a following mora within SHD is blocked by the OCP.

In summary, we have shown that $\mathrm{CB}$ differs significantly from $\mathrm{NB}$ with respect to the OCP which can be violated by HD in $\mathrm{CB}$. The application of the OCP in $\mathrm{CB}$ also provides crucial evidence for treating HTS in CB as involving two distinct rules. SHD is subject to the OCP, while HD is not. Furthermore we have seen that the effect of the OCP is not to either forbid any SHD or allow it to apply in full, but rather it allows SHD to partially apply if the OCP remains unviolated. We consider now, for completeness, how HTS applies across word boundaries.

4.4 HTS across word boundaries. In this sub-section we investigate whether a high spreads onto a following word and whether this spreading can also create a ternary domain. What we find is that a high tone on a word-final mora will spread onto a free word-initial mora of a following word. If there is a following high tone within the second word, no more spreading occurs and thus the resulting $\mathrm{H}$ tone span is binary (and not ternary). If there is no high tone in the second word, then spreading of the $\mathrm{H}$ in question continues on in an unbounded fashion to the end of the second word. We discuss examples of these in turn below.

Let us first consider the examples below in (30) of a final $\mathrm{H}$ spreading only to the first mora of the following word when another high follows within that word.

a. páápáàtìk-ìl-á Kápèèmbwá

'flatten for Kapembwa' /páapaatik-il-a $+\mathrm{H}_{\mathrm{F}}$ Kapembuá/

b. bélééng-èl-á Kápèèmbwá 'read for the Kapembwa' /béleng-il-e $+\mathrm{H}_{\mathrm{F}}$ Kapembuá /

c. lùk-á páànóònó

'weave a little' /luk-a $+\mathrm{H}_{2 \mathrm{~F}}$ paanóonó/

d. tù-lùk-í-ílé páànóònó 'we have woven a little' /tu-luk-il-ile $+\mathrm{H}_{2 \mathrm{~F}}$ paanóonó/

e. ì-cí-páàpá cí-sùmá 'good rind' /í-ci-paapá ci-sumá/ 
f. ù-lú-táàndá lú-sùmá $\quad$ 'good star'
/ú-lu-tandá lu-sumá/

The examples in (30a-c) show that a melodic high on the final vowel spreads only onto the first mora of the following word, if that second word has another high within it, even though there are other following low tone targets. This demonstrates that inter-word spreading creates a binary, rather than a ternary, domain. (30d) shows that the spreading of a final high also applies to a multiply linked high as in this case, which involves a melodic high assigned to V2 to the final vowel. Finally, examples (30e-f) show that the same constraints hold for lexical Hs in nominals as in these noun + adjective sequences. Consider now the following examples in (31) showing the interaction of inter-word spreading with the OCP.
a. páápáàtik-ill-á mú!lámù
'flatten for the brother-in-law' /páapaatik-il-a $+\mathrm{H}_{\mathrm{F}}$ mulámu/
b. bélééng-èl-á múllámù /béleng-el-a $+\mathrm{H}_{\mathrm{F}}$ mulámu/
'read for the brother-in-law'
c. tù-lùk-í́lé múllámù /tú-luk-il-ile $+\mathrm{H}_{2 \mathrm{~F}}$ mulámu/
'we have woven for the brother-in-law'
d. cùùlá mú-'kúlú /cuulá mu-kúlu/

As the examples in (31) show, inter-word spreading is not constrained by the OCP and applies even if a high tone immediately follows, resulting in a downstep of that following high. There is no difference with respect to the OCP between singly and multiply linked highs, and nominals (31d) also follow the same pattern. Thus inter-word spreading in these cases involves a binary domain and is not constrained by the OCP. Let us now consider cases of inter-word spreading where there is no high in the following word. Consider the examples in (32).
a. kàk-á cáángá
'tie the bush-baby!'
/kak-a $+\mathrm{H}_{2 \mathrm{~F}}$ canga/
b. lùk-á bwíínó
'weave well!'
/luk-a $+\mathrm{H}_{2 \mathrm{~F}}$ buino/

The examples in (32) show that a final high will spread in an unbounded fashion into a following toneless word.

Finally, we note that these inter-word spreading patterns also affect a high tone that was spread onto a word-final vowel via High Doubling at the word level. 
(33)
a. tù-kà-lás-á Kápèèmbwá
b. ú-kú-'lás-á mú!lámù
/ú-ku-lás-a mu-lámu/
c. í-cí-'bát-á cí-sùmá
/í-ci-báta ci-sumá/
d. tù-kà-lás-á cáángá
/tu-ka-lás-a canga/
'we will hit Kapembwa'
'to hit the brother-in-law'
'good duck'
'we will hit the bush-baby'

In each of the examples above, the $\mathrm{H}$ in the first word originates underlyingly on the penult. As described above, $\mathrm{HD}$ will spread that $\mathrm{H}$ onto the word-final TBU. At the phrasal level, this multiply linked $\mathrm{H}$, then undergoes spreading into the next word. Since there is a $\mathrm{H}$ later in the word in (33a-c), the $\mathrm{H}$ from the first word spreads only onto the first TBU of the second word. However, in (33d-e) where the second word is completely toneless, the spreading is unbounded. To account for the spreading in (30)-(33) we propose a domain juncture rule of Inter-word H Doubling as defined in (34). ${ }^{11}$

(34) Inter-word $\mathrm{H}$ Doubling: spreads a $\mathrm{H}$ linked to a word-final mora (be it singly or multiply-linked) onto the first mora of the following word

To sum up this section, the facts of local HTS in CB demonstrate that at least two doubling rules are at play to account for the surface ternary effects; what we have called HD and SHD. There are two factors motivating the postulation of two independent doubling rules: the two rules show different patterning with respect to the ability to spread onto a word-final vowel, and the two rules contrast in their interaction with the OCP. Running parallel to bounded spreading is unbounded spreading which allows a high to spread to the end of a stem if unimpeded by a following high or following constituent. Across word-boundaries an interword tone doubling rule is shown to spread a $\mathrm{H}$ into a following word. As has been shown, there is also important but systematic variation in the application of ternary spread with respect to the position of long vowels. We take up all these issues in the following section, where we propose an analysis to account for the observed distribution, and demonstrate the interaction of the proposed rules.

\footnotetext{
${ }^{11}$ Inter-Word Doubling, with varying constraints, is also found in other Bantu languages. See, e.g., Nyamwezi as discussed in Maganga \& Schadeberg (1992: 45).
} 


\section{Analysis: Accounting for CB spreading patterns}

In this section, we formalize the tonal processes discussed above and exemplify their application in some derivations. Let us first consider the rule of ternary spreading. As explained and justified at some length above, ternary spreading is the result of two sequential processes. The first rule is that of High Doubling, which spreads a high tone onto the following mora. It is formalized in (35) below.

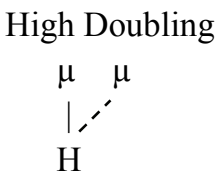

Prosodic domain of application: Word

Iterative: No

Subject to OCP: No

It should be noted that this particular rule contains no reference to syllables. This predicts, quite correctly, that if the underlying $\mathrm{H}$ is on the first mora of a bimoraic syllable, then High Doubling simply spreads it onto the second mora of that same syllable (see (28)). If, on the other hand, the $\mathrm{H}$ is on the sole mora of a syllable or on the second mora of a bisyllabic syllable, then the $\mathrm{H}$ will spread onto the first mora of the following syllable (see (24a-b), (25), (29)).

The next rule, which creates the ternary patterns, is Secondary High Doubling, formalized below.

Secondary High Doubling

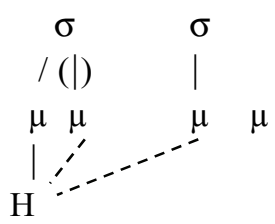

Prosodic domain of application: Word

Iterative: No

Subject to OCP: Yes

This rule spreads a $\mathrm{H}$ onto the first mora of the following syllable. Thus it makes reference to both morae and syllable nodes. If the mora bearing the $\mathrm{H}$ is the sole one of the syllable, then 
the spreading will be to a single mora (see (18a-d)). If the mora bearing the $\mathrm{H}$ is the first of two within a syllable, then the $\mathrm{H}$ spreads through the tautosyllabic mora and then into the following syllable (see (18e-h). Hence the optionality (indicated by parentheses) of the second mora in the first syllable. Unlike High Doubling, the Secondary Doubling rule is constrained by the OCP. As discussed earlier, there are cases where the OCP blocks SHD completely ((27), (28), (29a-b)), and cases involving partial spreading, only to the tautosyllabic mora (29c-e). Finally, as we saw in (20), SHD is also different from HD in that it never spreads a $\mathrm{H}$ onto a word-final TBU. Thus, the presence of the final mora in the rule which will ensure the target of spreading is never the domain-final TBU. ${ }^{12}$

Our claim is that in terms of the prosodic hierarchy, both HD and SHD occur at the domain of the prosodic word. Further justification for this will be seen as we now turn to phrase-level rules.

The rule of Inter-word H Doubling, as described and illustrated in sub-section 4.3 spreads a word-final $\mathrm{H}$ onto the first mora of the following word. This is formalized below.

Inter-Word Doubling

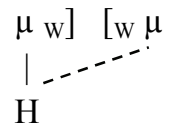

Prosodic domain of application: Word juncture rule within a Phrase ${ }^{13}$ Iterative: No

Subject to OCP: No

As shown, this rule simply spreads a $\mathrm{H}$ from the word-final mora of one word onto the wordinitial mora of the following word. As we demonstrated above, however, the rule applies not only to a $\mathrm{H}$ which is underlyingly word-final ((30), (31)), but also to a $\mathrm{H}$ which has spread to the word-final mora through $\mathrm{H}$ Doubling (33). Thus, even though the structural description of HD and IWD are very similar, it is not possible to reduce their effects to a single rule, since there are cases where HD feeds IWD, i.e., where they both apply. This is illustrated below in (38). This ordering falls out straightforwardly, if we assume, following the prosodic hierarchy of Selkirk 1984, that all word-level rules, here HD, occur prior to phrasal rules, here IWD.

\footnotetext{
12 Although the Secondary High Doubling rule is rather complex in its current formalization, its necessity is not in question because it is shown to be subject to different constraints in comparison to High Doubling. The formalization of SHD might well be able to be simplified within a different theoretical approach. We leave this to future work.

${ }^{13}$ The precise type of phrase (e.g. phonological, intonational) as well as the interaction of these various tonal processes in a variety of more complex phrases is actively under study by the current authors.
} 
(38)

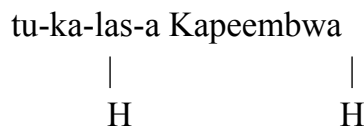

tu-ka-las-a Kapeembwa<smiles>C1CC1</smiles>

$\mathrm{H}$

tu-ka-las-a Kapeembwa<smiles>[Mg][AlH2]</smiles>

$\mathrm{H}$
UR

HD

$\mathrm{H}$

IWD

Finally, we note that the effects of IWD cannot be subsumed by SHD since it has been shown that the former process is not subject to the OCP (31), while the latter is (27) - (29).

The final process to consider within the tonal interactions that we have described above is Unbounded Spreading. This is formalized below.

Unbounded Spreading

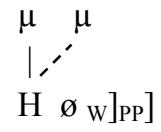

Prosodic domain of application: Phonological Phrase

Iterative: Yes

Subject to OCP: $\mathrm{n} / \mathrm{a}$

As presented and justified above, Unbounded Spreading will apply to the rightmost $\mathrm{H}$ tone in a phrase-final word. This explains the presence of both a right-edge word and PP boundary within the rule. Any $\mathrm{H}$ which does not meet this structural description will undergo $\mathrm{HD}$ and SHD which, as the elsewhere case, requires no such prosodic boundary specifications within the rule. Unbounded Spreading is a phrase-level rule which follows Inter-Word Spread, as illustrated below for (32a). 
$\mathrm{H}_{\mathrm{F}}$<smiles>[14CH3][MgH]</smiles>

kak-a caanga<smiles></smiles>

$\mathrm{H}$

kak-a caanga

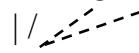

$\mathrm{H}$
Docking of $\mathrm{MH}$ onto FV

Inter-word Doubling

Unbounded Spreading

If Unbounded Spreading were a word-level rule, like HD and SHD, it would only apply vacuously here, since the $\mathrm{H}$ is already on the word-final TBU. However, as a phrase-level rule, ordered after Inter-word Spread, it will apply in cases like the one above, since at the time of its application there is a $\mathrm{H}$ (not followed by any other $\mathrm{H}$ ) in the phrase-final word.

\section{Previous analyses of ternary spread}

One of the central issues in phonology with respect to processes involving possible cases of ternary spread is that such processes are unexpected and disfavored, on grounds of their violation of contiguity or adjacency between the trigger of a process and the phonological target (see, e.g., Odden 1994). Our proposed analysis of ternary spread in CB as involving two separate rule applications is amply motivated by the fact that the two rules are, as shown above, clearly subject to different constraints. This means that first language learners of CB, who have no NB input or experience, are able to create the two separate rules in their L1 phonological system because they will encounter evidence for doing so. In this sense, the proposed analysis is justified and in keeping with adjacency requirements between the trigger and the target. ${ }^{14}$ We now briefly consider several cases of ternary spread discussed in the literature in order to situate the $\mathrm{CB}$ case in a comparative perspective.

\footnotetext{
${ }^{14}$ Cases of ternary shift as, for example, discussed for Sukuma (Goldsmith 1985, Batibo 1991, among others) or Dembwa Taita (Odden 2001), including cases involving both tone shift and doubling as in Saghala (Patin 2009), also raise issues for contiguity and locality. See the cited references for possible analyses.
} 
6.1 Perspectives adopting a staged approach. A number of analyses show evidence for the postulation of two or more rules that cumulatively derive ternary spread, in contrast to a single phonological rule. These analyses generally involve intermediate stages that do not run afoul of locality constraints. An early approach to ternary spread comes from Myers (1987), a seminal work on the tone of Shona dialects. In north-central dialects (Zezuru, Korekore, Northern Karanga) and only in the word and stem domains, a high tone spreads two syllables to the right (ternary spread), in contrast to higher domains where rightward spread is unrestricted and spreads to any number of syllables. The source of ternary spread is unrestricted and can be a high-toned verb root or a high-toned non-verb stem morpheme (object or subject marker). Myers accounts for this by arguing that all tones are underlyingly specified in the relevant dialects, and at least three rules are involved in the generation of the surface ternary spread. Thus, in a sequence of H-L-L-L at the stem or word level, in the relevant dialect, a low tone preceded by a singly linked high tone is first delinked to derive H$\varnothing$-L-L. The high tone then undergoes rightward spread up to the syllable containing a low tone but further spread is blocked by the line crossing constraint. At this point the high tone has spread two syllables to the right creating a HL on the third syllable, which subsequently undergoes a rule of simplification to $\mathrm{H}$ resulting in the final form $\mathrm{H}-\mathrm{H}-\mathrm{H}-\mathrm{L}$, i.e., with ternary spread. Cassimjee (1986) adopts Myers' approach to explain similar ternary effects in Venda. Hewitt \& Prince (1989) reanalyze Myers' analysis for N. Karanga opting for a root level HTS rule that precedes a general HTS rule. Similar but slightly different from this approach, Odden (1981) proposes an analysis for ternary spread in Karanga as a rule of unbounded HTS followed by a tone retraction rule.

A clear case of distinct domains of rule application in the generation of ternary spread is provided by Ikalanga (S16), where Hyman \& Mathangwane (1998) argue for three HTS rules applying in three distinct domains: the prosodic stem level, the phonological phrase level and the utterance level. According to Hyman \& Mathangwane, in the cases where ternary spread occurs in Ikalanga, three HTS rules occur in succession but at different levels. Consider the examples below for lexically toneless nyebunusa 'raise' in (41a) and lexically high-toned poteleka 'surround' in (41b). 
(41)
Stem level
(HTS1)
Phrase level
(HTS2)

a. nyebunus- $<\mathrm{a}>$

b. potelek-<a $>$

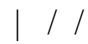

$\mathrm{H}$

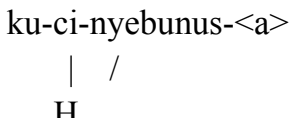

$\mathrm{H}$

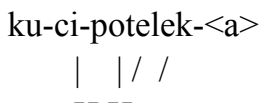

$\mathrm{H} \mathrm{H}$
Utterance level

(HTS3)

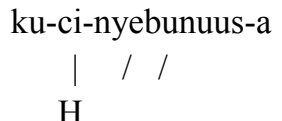

ku-ci-poteleek-a

| | / /|

$\mathrm{H} \mathrm{H}$

In (41) stem level rule HTS1 spreads a high tone where present to every syllable in the verb stem to the exclusion of the final vowel, which for this reason is treated as 'extrametrical' or falling outside the domain of HTS1 application. HTS1 applies in the same fashion in longer verb stems. Phrase level HTS2 spreads a rightmost high tone one syllable to the right (i.e., binary spread). We see this in (41a), but not in (41b), because final vowel extraprosodicity still holds. This means that (41b) does not provide a context for HTS2 to apply. At the utterance level HTS3 applies to spread a rightmost high one syllable to the right and in contrast to the other levels, final vowel extraprosodicity does not apply at this level. HTS3 results in apparent ternary spread in (41a). ${ }^{15}$ Hyman \& Mathangwane convincingly demonstrate that the three rules are cumulative with respect to deriving ternary spread in (41a), for example. The rules apply in different domains and are subject to different conditions. HTS1 is iterative, targeting every visible vowel in its domain, while HTS2 \& 3 are non-iterative. HTS1 \& 2 are not blocked by depressor consonants, while HTS3 is blocked. The three rules also differ with respect to their sensitivity to the OCP: HTS2 is subject to the OCP but HTS3 is not. The status of the OCP with respect to HTS1 is unclear.

In contrast to Ikalanga, there is no evidence in $\mathrm{CB}$ to suggest that our proposed rules of primary and secondary high tone doubling apply at different levels of the prosodic hierarchy. As argued above, Secondary High Doubling does not apply across word boundaries and is restricted to the word level at which primary High Doubling clearly applies.

6.2 Evidence suggesting a single rule. Creissels (1998) discusses an apparent case of ternary spread in Tswana in the disjunctive forms of the Present Positive Infinitive in hightoned verbs occurring without object markers. In verb forms belonging to this paradigm, words with less than 4 syllables show HTS to every syllable, while those with more than 4

\footnotetext{
${ }^{15}$ Differences in tone spreading patterns also arise from the presence/absence of an intonational phrase (IP) boundary marked by penultimate lengthening in Ikalanga. Bi-syllabic verbs also show some contrasting patterns whose details are not relevant for the current discussion. See Hyman \& Mathangwane (1998) for complete distributional facts and analysis.
} 
syllables consistently show high tone on the first three syllables. Consider the examples below from Creissels (1998: 158). ${ }^{16}$
a. gò já (gó á tlhókàfâlà)
b. gò tsómá (gó fá báthó nàmà)
c. gò rékísá (gó thúsá ká màdí)
d. gò símólól-à (gò siámè)
e. gò thókómólòg-à (gà gó à síámè)
f. gò símólólèlàn-à (gó siámè)
'It is necessary to eat'
'Hunting provides people with meat'
'Selling helps financially'
'It is good to begin'
'It is not good to be careless'
'It is good to begin for one another'

As seen in (42a-c) a high tone spreads to the end of the domain in monosyllables, disyllables and three syllable verb forms. This contrasts with (42d-f) where HTS is ternary. Creissels (1998: 159) treats this apparent ternarity as the result of the expansion of a high tone domain with a range of two syllables, followed by a rule of default $\mathrm{L}$ tone insertion on the remaining syllables. Creissels thus circumvents direct reference to ternarity by formulating the rule as a restriction on the size of the target, two syllables, which is easily motivated phonologically. It is difficult to see an alternative (non-ternary) account to these data given the clear contrast in terms of stem size. One can speculate that the rule could result from analogy with the (probably more frequent) less than 4 syllable forms, from the point of view of duration of high tone span.

Similar to Tswana, in Dagbani, a Gur language of Ghana, Hyman (1993) shows that a staged analysis of the ternary spreading facts in this language is far from satisfactory. In Dagbani, a high tone spreads two syllables to the right so that an underlying sequence of H-L$\mathrm{L}$ surfaces as $\mathrm{H}-\mathrm{H}-\mathrm{HL}$. Hyman distinguishes two spreading rules for Dagbani, HTS1 and HTS2, which cumulatively derive the ternary effect. These two rules, unlike Ikalanga above, cannot be separated in terms of their domain of application, since both apply at the postlexical level. Thus, the postulation of two rules in this case, is merely to accord with the constraints of phonology although the data show evidence for a single rule.

Finally, in more recent work Johnson \& Paster (2012) argue that the Shona dialect of Manyika, from Mutasa, manifests a case of tone tripling that is accomplished by a single rule. Johnson \& Paster (2012) demonstrate that in this dialect (similar to Tswana above) verb stems of one to three syllables show HTS to the final syllables while longer ones show ternary spread with the caveat that longer forms of 5 or more syllables show HTS up to the penult. They account for these facts by proposing two rules: High Tone Tripling and Penultimate Spreading, ordered in this way to explain why 3-syllable forms surface with high tone on the final vowel. Penultimate Spreading also has independent motivation, in that it is the only rule

\footnotetext{
16 The Tswana examples are presented here in Tswana orthography so note that the phonetic sound qualities of these forms are not represented (see Creissels 1998). Information following the verb stem is set off in parentheses to delimit the verb stem under discussion here.
} 
that applies when the source of HTS is a morpheme outside the verb stem, such as an object or subject marker. In this case all verb forms undergo penultimate spreading regardless of size. Also like in Tswana, High Tone Tripling in Manyika is limited to particular TAMs with the rule not applying in some TAMs.

In Copperbelt Bemba, all the evidence points to two rules, rather than a single one, as responsible for the ternary domains. One interesting difference between $\mathrm{CB}$ and the cases investigated in this section is that ternary spread in Bemba is a widespread and across the board phenomenon and that unlike in Tswana and Manyika, there is no restriction in terms of size of verb stem or in terms of the TAMs that are affected. The rule is in this sense purely phonological. There is also no restriction with respect to domain or level, unlike in Ikalanga, so that the rule applies within a verb stem (if a high tone follows) and in larger domains (if another constituent follows).

\section{Summary \& Conclusion}

In this paper, we have provided the first description of the tonal patterns of Copperbelt Bemba. While being very similar to much better known and documented Northern Bemba, the variety we describe here is crucially and interestingly different in its tonology. While both dialects exhibit unbounded and bounded spreading, local spreading in Copperbelt Bemba has been shown to be ternary, rather than binary. While bounded spreading in NB is always constrained by the $\mathrm{OCP}$, we have shown that the story in $\mathrm{CB}$ is more complex. At first glance, it appears that the OCP constrains local spreading in $\mathrm{CB}$ in some cases but not others. We have shown that the OCP effects in this variety are in fact completely regular and systematic. The reason spreading seems to be constrained by the OCP in some cases but not others falls out directly from our analysis which maintains that the local, ternary spreading in $\mathrm{CB}$ is the product of two distinct local spreading processes, not a single ternary one. The first rule is High Doubling which spreads a $\mathrm{H}$ to the following mora, while the second, Secondary High Doubling, spreads the $\mathrm{H}$ to the first mora of the following syllable. These two processes differ in two major respects: first, HD is not subject to the OCP, while SHD is, and second, HD can spread a H onto a word-final TBU, while SHD cannot. We then showed that these two wordlevel rules feed two phrasal rules; Inter-word Doubling and Unbounded Spreading. The combined effect of all these rules can actually spread an underlyingly penultimate $\mathrm{H}$ from one word all the way to the ultima of the following word.

In addition to making a robust descriptive contribution to the field of Bantu tone, the present study makes analytic and comparative ones as well. Ternary spreading is relatively rare, and some have suggested it violates commonly held assumptions about adjacency. We therefore compare the $\mathrm{CB}$ case here with other reported cases in the literature. While some cases are analyzed as a single ternary process, a number of others are the result of two sequential processes. We propose to add CB to the second group. From a comparative / historical perspective, the present study allows us to contrast two dialects which are nearly 
identical morphologically, syntactically and from a segmental phonological perspective, but which differ interestingly in their tonology. More comparative work is needed to demonstrate how these differences emerged, but one possible account would be to assume that the ternary patterns seen in $\mathrm{CB}$ are relatively recent innovations from an earlier system looking like that of NB. ${ }^{17}$ Figuring out exactly how a system with binary spreading always subject to the OCP could become a system exhibiting ternary spreading with violable OCP patterns is a worthy matter of future study.

${ }^{17}$ Philippson (1991: 136) similarly suggests that ternary shifting in Sukuma may have evolved from binary shifting, which appears in the closely-related language Nyamwezi. We thank a reviewer for pointing this out to us. 


\section{References}

Batibo, Herman. 1991. The two directional tone melody spread in Sukuma. In Kathleen Hubbard (ed.) Proceedings of the Seventeenth Annual Meeting of the Berkeley Linguistic Society: Special Session on African Language Structures. Berkeley: BLS.

Bickmore, Lee. 1997. Problems in constraining High Tone Spread in Ekegusii. Lingua 102(4). 265-290.

Bickmore, Lee. 2000. Downstep and fusion in Namwanga. Phonology 17(3). 297-333.

Bickmore, Lee. 2007. Cilungu Phonology. Stanford: Center for the Study of Language and Communication.

Cassimjee, Farida. 1986. An autosegmental analysis of Venda tonology. Champagne/Urbana: University of Illinois dissertation.

Creissels, Denis. 1998. High tone domains in Setswana. In Hyman, Larry M. \& C. Kisseberth (eds.), Theoretical aspects of Bantu tone. 195-229. Stanford: CSLI Publications.

Givón, Talmy. 1970. On ordered rules and the modified base of ChiBemba verbs. African Studies 29. 47-54.

Givón, Talmy. 1971. Dependent models, performatives, factivity, Bantu subjunctives and what not. Studies in African Linguistics 2(2). 61-81.

Givón, Talmy. 1972. Studies in CiBemba and Bantu Grammar. Studies in African Linguistics, Supplement 3, Vol. 3.

Givón, Talmy. 1974. Studies in ChiBemba and Bantu grammar. Los Angeles: Department of Linguistics and the African Studies Center at the University of California.

Givón, Talmy. 1976. Some constraints on Bantu causativization. In M. Shibatani (ed.), Syntax and Semantics 6: The grammar of causative constructions. London: Academic Press.

Goldsmith, John. 1985. On tone in Sukuma. In Didier Goyvaerts (ed.), African Linguistics: Essays in Memory of M. W. K. Semineke. Amsterdam/ Philadelphia: John Benjamins. Goldsmith, John. 1987. Stem tone patterns of the Lacustrine Bantu languages. In David Odden (ed.), Current Approaches to African Linguistics (vol. 4). 167-177. Dordrecht: Foris.

Guthrie, Malcom. 1945. The tonal structure of Bemba. University of London dissertation. Hewitt, Mark and Alan Prince. 1989. OCP, locality and linking: The N. Karanga verb. In Fee, Jane \& Kathryn Hunt (eds.), Proceedings of the West Coast Conference on Formal Linguistics 8, 176-191. Stanford: Stanford Linguistics Association.

Hoch, E. Rev. 1955. A Bemba Grammar with Exersises. Chinsali: Language Centre Ilondola. Hyman, Larry M. 1992. Velar palatalization in Cibemba: A "non-duplication" problem. Linguistique Africaine 8. 55-71.

Hyman, Larry M. 1993. Structure preservation and postlexical tonology in Dagbani. In Kaisse, Ellen \& Sharon Hargus (eds.), Studies in Lexical Phonology. 235-254. New York: Academic Press. 
Hyman, Larry M. 1994. Cyclic phonology and morphology in ChiBemba. In Cole, Jennifer S. \& Charles Kisseberth (eds.), Perspectives in Phonology. 81-112. Stanford: CSLI Publications.

Hyman, Larry M. 1995. Minimality and prosodic morphology of ChiBemba imbrication. Journal of African Languages and Linguistics 16. 3-39.

Hyman, Larry M. \& Ernest Byarushengo. 1984. A model of Haya tonology. In Clements George N. \& John Goldsmith (eds.), Autosegmental Studies in Bantu Tone. 53-104. Dordrecht: Foris.

Hyman, Larry M. \& Francis Katamba. 1993. A new approach to tone in Luganda. Language 69. 34-67.

Hyman, Larry M. \& Joyce T. Mathangwane. 1998. Tonal domains and depressor consonants in Ikalanga. In Hyman, Larry M. \& Charles Kisseberth (eds.), Theoretical aspects of Bantu tone. 195-229. Stanford: CSLI Publications.

Hyman, Larry, M. \& Armindo Ngunga. 1994. On the non-universality of tonal association "conventions": Evidence from Ciyao. Phonology 11. 25-68.

Johnson, Martha \& Mary Paster. 2012. Manyika verbal tonology. Ms. Pomona College.

Kaplan, Aaron. 2008. Peak delay and tonal non-iterativity. Rutgers Optimality Archive 9720508.

Kashoki, Mubanga E. 1968. A phonemic analysis of Bemba. Manchester: Manchester University Press.

Kashoki, Mubanga E. 1972. Town Bemba: A sketch of its main characteristics. African Social Research 13. 161-186.

Kula, Nancy C. 2002. The phonology of verbal derivation in Bemba. LOT Dissertation Series 65. Utrecht: Holland Academic Graphics.

Mann, Michael. 1977. An outline of Bemba grammar. In Languages in Zambia, Vol. I. Lusaka: University of Zambia, Institute for African Studies.

Marten, Lutz and Nancy C. Kula. To appear. Benefactive and substitutive applicatives in Bemba. Journal of African Languages and Linguistics.

Maganga, Clement and Thilo C. Schadeberg. 1992. Nyamwezi: grammar, vocabulary, texts. Cologne: Rüdiger Köppe Publishing Co.

Myers, Scott. 1987. Tone and the structure of words in Shona. New York: Garland Press.

Myers, Scott. 1999. Tone association and F0 timing in Chichewa. Studies in African Linguistics 28(2): 215-239.

Odden, David. 1981. Problems in tone assignment in Shona. University of Illinois dissertation.

Odden, David. 1986. On the Role of the Obligatory Contour Principle. Language 62(2). 353383.

Odden, David. 1987. Predictable tone systems in Bantu. In Hulst, Harry van der \& Norval Smith (eds.), Autosegmental studies on pitch accent. 225-252. Dordrecht: Foris.

Odden, David. 1994. Adjacency parameters in phonology. Language 70. 289-330. 
Odden, David. 2001. Tone shift and spread in Taita I. Studies in African Linguistics 30(1). 75110.

Patin, Cedric. 2009. Tone Shift and Tone Spread in the Saghala Nominal Phrase. Faitsde Langue - Les Cahiers 1. 230-247.

Philippson, Gerrard. 1998. *HH and *HL tone patterns in Bemba and the Bemba tone system. In Hombert, Jean-Marie, and Larry M. Hyman (eds.), Bantu Historical Linguistics. Stanford: CSLI Publications, 395-411.

Philippson, Gerrard. 1991. Tons et accents dans les langues bantu d'Afrique Orientale: étude comparative, typologique et diachronique. Université Paris V, Doctorat d' Etat.

Sambeek, van. J. 1955. A Bemba Grammar. London: Longmans, Green \& Co.

Selkirk, Elisabeth. 1984. Phonology and Syntax: the relation between sound and structure. Cambridge: MIT Press.

Sharman, John, C. \& Achille E. Meeussen. 1955. The representation of structural tones, with special reference to the tonal behavior of the verb in Bemba, Northern Rhodesia. Africa: Journal of the international African Institute 25(4). 393-404.

Sharman, John, C. 1956. The tabulation of tenses in a Bantu language (Bemba: Northern Rhodesia). Africa 26. 29-46.

Spitulnik, Debra. 1999. The language of the city: Town Bemba as urban hybridity. Journal of Linguistic Anthropology 8(1). 30-59. 
Lee S. Bickmore

Department of Anthropology

University at Albany

1.bickmore@albany.edu

Nancy C. Kula

Department of Language and Linguistics

University of Essex

nckula@essex.ac.uk
Received: 27 Nov 11

Accepted: 12 Dec 12

Revisions: 08 Dec 2013 